African Journal of Educational Studies in Mathematics and Sciences Vol. 16, No. 1. 2020

\title{
Ways School Leaders Support the Teaching of Chemistry
}

\author{
Edwin Byusa $^{1}$, Edwige Kampire ${ }^{2} \&$ Adrian Rwekaza Mwesigye ${ }^{3}$
}

\begin{abstract}
The study aims to reinforce the effective teaching of chemistry in secondary schools through the support of the school leadership in the implementation of the competence-based curriculum (CBC). Interviews were organised and conducted with five headteachers and five deputy headteachers from ten selected schools. The results confirmed that the support provided by the school leadership in teaching chemistry was dominated by $30 \%$ of respondents at visiting teachers in classes, provision of some basic teaching materials and encouraging teachers to work in the chemistry department for mutual support and professional growth. However, in some schools, there is a need for prioritising continuous professional development (CPD) opportunities, feedback meetings and analysing school data for decision making. Therefore, this study recommends more efforts in CPDs, avail enough teaching aids and hold the pedagogical review and learning meetings lead by headteachers; analyse and use the school data for continuous improvement and build the school on tangible evidence in positive learning outcomes. Plus more support in engaging learners doing chemistry rather than just giving them chemistry books. Transformational leadership is needed, where all stakeholders share the same vision and mission of the school.
\end{abstract}

Keywords: $\quad$ competence-based curriculum; chemistry; continuous professional development; headteacher; deputy headteacher; support in teaching

\section{Introduction}

In general, teachers choose to prioritise passive teaching techniques, mainly the chalk and talk with the view that it allows them to cover the chemistry content during the allocated time of the school calendar and it was found that it is not necessarily the case (Byusa, Kampire, \& Mwesigye, 2020). Again, it was found that this teaching style of passive teaching has many limitations to chemistry education (Tenaw, 2015). Therefore, the teacher-centred approach is nowadays being replaced by the learner-centred approach worldwide. The later favours learners as they are at the centre of the learning, where they are fully engaged in the whole teaching and learning process. Its effectiveness on learners' performance is observed (Michael, 2006).

There is a need for support from headteachers for this positive change in teaching and learning processes. Headteachers are responsible for the overall, day to day management of all activities at school (Naz \& Tatlah, 2011), and they are, therefore, the key of any significant change at

\footnotetext{
${ }^{1}$ Edwin Byusa, PhD student in Chemistry Education at the African Centre of Excellence for Innovative Teaching and Learning Mathematics and Science (ACEITLMS), University of Rwanda College of Education (UR-CE). Kayonza, Rwanda. PO Box: 55 Rwamagana. E-mail: byedwin@yahoo.fr

${ }^{2}$ Edwige Kampire (PhD), University of Rwanda College of Education (UR-CE), Department of Mathematics, Science and Physical Education, Kayonza, Rwanda. PO Box: 55 Rwamagana, E-mail: edkampire@gmail.com

${ }^{3}$ Adrian Rwekaza Mwesigye (PhD), Associate Professor at the Mbarara University of Science \& Technology (MUST), Department of Educational Foundations and Psychology, Mbarara, Uganda. E-mail: arm@must.ac.ug

Open Access article distributed under the terms of the Creative Commons Attributions License [CC BY-NC-ND 4.0] http://creativecommons.org/licenses/by-nc-nd/4.0. DOI: https://dx.doi.org/10.4314/ajesms.v16i1.5
} 
their schools. It is the similar case in Rwanda where the headteacher is in charge of any technique that can be applied to improve the quality education in the school that he or she is managing (Republic of Rwanda, 2016). To improve the learner-centred approach, Rwanda has adopted the CBC in 2015.

The $\mathrm{CBC}$ was designed from the pre-primary to secondary education in Rwanda. The CBC is designed to allow teachers to help learners develop the required subject and grade-level specific outcomes through learner-centred pedagogy (Ministry of Education, 2015). The CBC started to be implemented in 2016 (Ndihokubwayo, Mugabo, Byusa, \& Habiyaremye, 2019; Ndihokubwayo \& Murasira, 2019).

For the effective implementation of the $\mathrm{CBC}$, teachers were inducted through cascade training model and continued to be engaged in CPD opportunities (Ndihokubwayo et al., 2019; Ndihokubwayo \& Murasira, 2019) to improve their teaching approaches. However, some teachers of chemistry are still struggling to engage learners efficiently in the teaching and learning process due to the lack of enough time to conduct hands-on activities in chemistry courses in many schools (TheNewTimes, 2017). Consequently, teachers are applying inappropriate teaching techniques which lead to the poor performance of learners. In addition, regardless of how supported and prepared, some new teachers find themselves challenged by teaching due to lack of self-confidence and experience (Schleicher, 2012).

This study aims to reinforce the effective implementation of the CBC in the chemistry lessons. With a particular emphasis on headteachers' and deputy headteachers' support to the teaching and learning process towards the improvement of learning outcomes in chemistry classes. By building on headteachers' and deputy headteachers' experience in leading positive learning outcome in the education system and then, the chemistry classes are concerned. Specifically, the study investigates the headteachers' appreciation in the teaching techniques in chemistry subjects for senior two classes (S2) (age range 14-16). It is the second grade of secondary school after completing six years of primary school in the Rwandan education system (World Bank, 2003). Additionally, this study assesses the headteachers' support to the smooth shift from teacher-centred to learner-centred approach in their respective schools.

The following research questions guided this study for a better understanding of the headteacher's support to the teaching practice of chemistry in S2:

1. What do headteachers do to enhance the students' academic performance of chemistry in $\mathrm{S} 2$ classes?

2. What support is needed from headteachers for effective teaching and learning of chemistry in $\mathrm{S} 2$ classes?

\section{Materials and methods}

In this study, the phenomenology research design was used to study the individual experience of school leadership in supporting the teaching of chemistry in S2 classes. The study was conducted in ten selected secondary schools of Gasabo district in Rwanda. The selection of those ten schools was motivated by the fact that they represent the Gasabo district in terms of geographical coverage as guided by both district and sector education officials.

Interviews were conducted at each school. They were held from April 2019 to July 2019 depending on the availability of either headteacher or deputy headteacher. The University Lecturers established the validity of the interview guide. In addition, four chemistry teachers 
and one postgraduate student in chemistry education found the interview guide valid. The pilot of the guide contributed to its clarity.

The interview data were analysed through the content analysis by grouping information in similar themes based on the research objective. An attempt to identify patterns and causal link in the theme was done. Results were compared to the research questions, and then conclusions and recommendations have been recorded and associated interpretations to justify the findings and or suggestions. The purpose was to recognise the current situation (Creswell \& Garrett, 2008) in selected secondary schools in chemistry education

The ethical issues have been observed. The participant identification was confidential. Before any data collection, consent has been obtained from the participant, and participation was voluntary after getting all detailed information about the study. There is no expected risk for participants taking part in the study, and no compensation was given to them. During the analysis, databases have been password-protected to restrict free access. The ethical approval was granted by the Research and Innovations Unit of the University of Rwanda, College of Education, before starting the field data collection. Then after the Gasabo District has authorised this research too.

\section{Results}

The findings of this study are presented in this section. In total, five headteachers and five deputy headteachers from the ten schools took part in the interview. The $30 \%$ were females, and $70 \%$ were males. Among the headteachers involved in the study, 20\% were female, and $80 \%$ were male whereas for deputy headteachers, females represented $40 \%$ and males $60 \%$.

Figure 1 shows that teaching techniques of chemistry that headteachers used to observe in S2 vary from one teacher to the other. Whereas the preference of the headteachers and deputy headteachers on the teaching techniques to be used in teaching chemistry in S2 is dominated by group work.

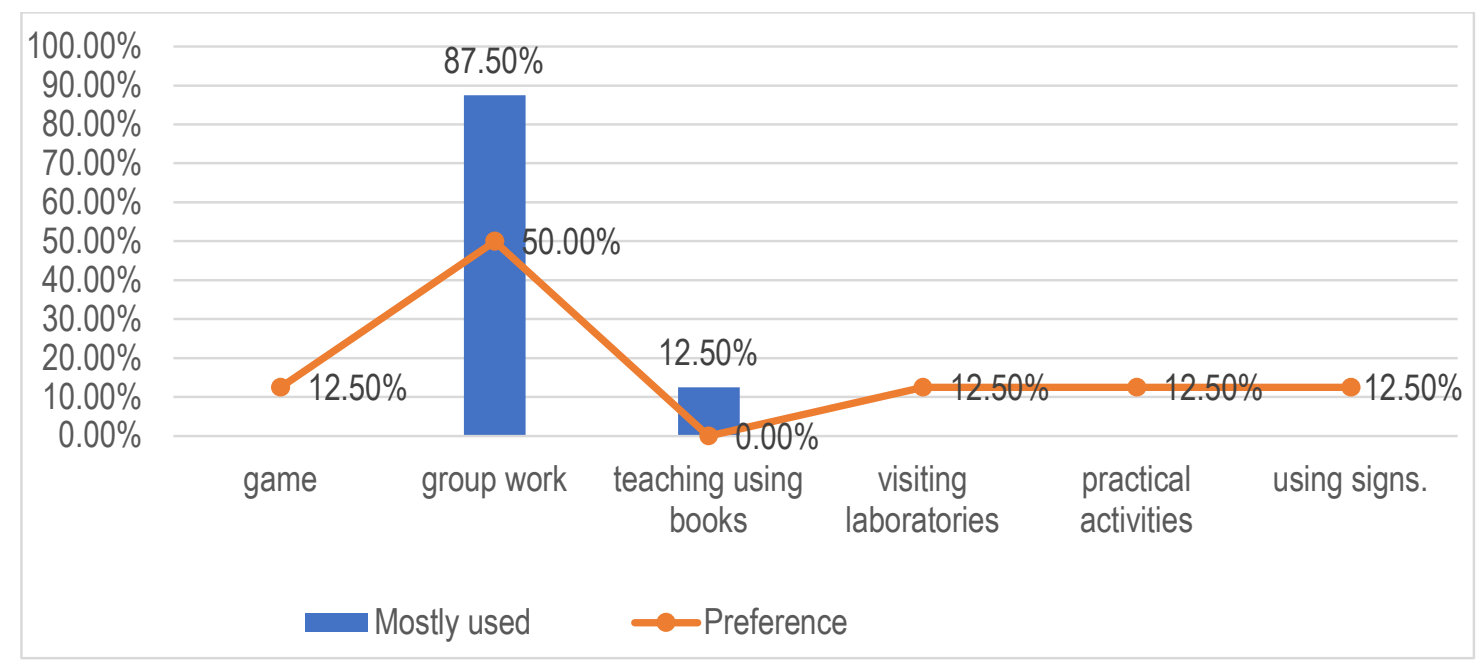

Figure 1 Types, frequencies and preference of teaching techniques in chemistry classes

From the respondents, $87.5 \%$ of headteachers and deputy headteachers reported that they were using observation guide while teachers of S2 chemistry were delivering the lessons applying group work which is one of the learner-centred approaches. The remaining $12.5 \%$ of them, 
confirmed to see teachers using books. Although, other techniques, including the use of games, visiting laboratories, conducting practical activities and signs, are being used in schools, at a lower level. Because all other techniques combined are taking 50\% of applied techniques and the rest $50 \%$ is taken by the group work teaching technique only. Below is the quote of respondents:

"In most cases, teachers use groups. We usually have a large number of students. Therefore, to reach all the students or at least to reach a large number of students, during the teaching and learning process in the classroom; we have found that using groups is an excellent technique that allows the teacher to reach a large number of students. Groups are being used daily".

"Teachers in my school use mostly group discussions, because of the large number of students in our classes. It is a useful technique which is productive, as the strong leaners help the weak ones. Therefore, in group discussions, students help one another".

"The one which comes quicker than others and mostly used not only in chemistry is that of group formation. Because most of the time there is no other special resource required, only the presence of the teacher, learners and desks..."

"As the competence-based curriculum emphasises on the teamwork, this technique of group work is used most of the time. Children support each other..."

".... I visit them in the class observations, I found that they use group work every day. Because we have had pieces of training about the $C B C$, they use group work. It is beneficial to them in their daily life".

Half of the respondents reported preferring group work activity and can recommend it to others. Other techniques were appreciated by headteachers and deputy headteachers like visiting laboratories at $12.5 \%$, using games at $12 . \%$, using practical activities at $12.5 \%$ and using signs at $12.5 \%$. However, one of the respondents has a preference in using books for teaching chemistry in S2 even though it was observed being used by $12.5 \%$ of respondents:

"Considering the youth, we have today. I can recommend this technique of using games. In games, a child does not get bored.... What is learnt from games is easily retained and cannot be forgotten. By considering the children, we have there is no one who can get bothered by games".

"Field trip and doing experiments in the laboratory. Because when students use labs, it helps them to perform better".

"I can recommend them to use group work where teaching aids are used. Because it helps learners by supporting each other's ".

"I can recommend them to tell their teachers to use group discussions...."

".... this technique of group work is one of the techniques that make learners being active. We have had a chance to have stakeholders who helped us to increase its use at our school, they have even shown us the role of this technique in increasing the understanding and the thinking of children..."

Figure 2 summarises areas that were identified to require too much attention by headteachers toward improving chemistry teaching in S2 classes. 
African Journal of Educational Studies in Mathematics and Sciences Vol. 16, No. 1. 2020

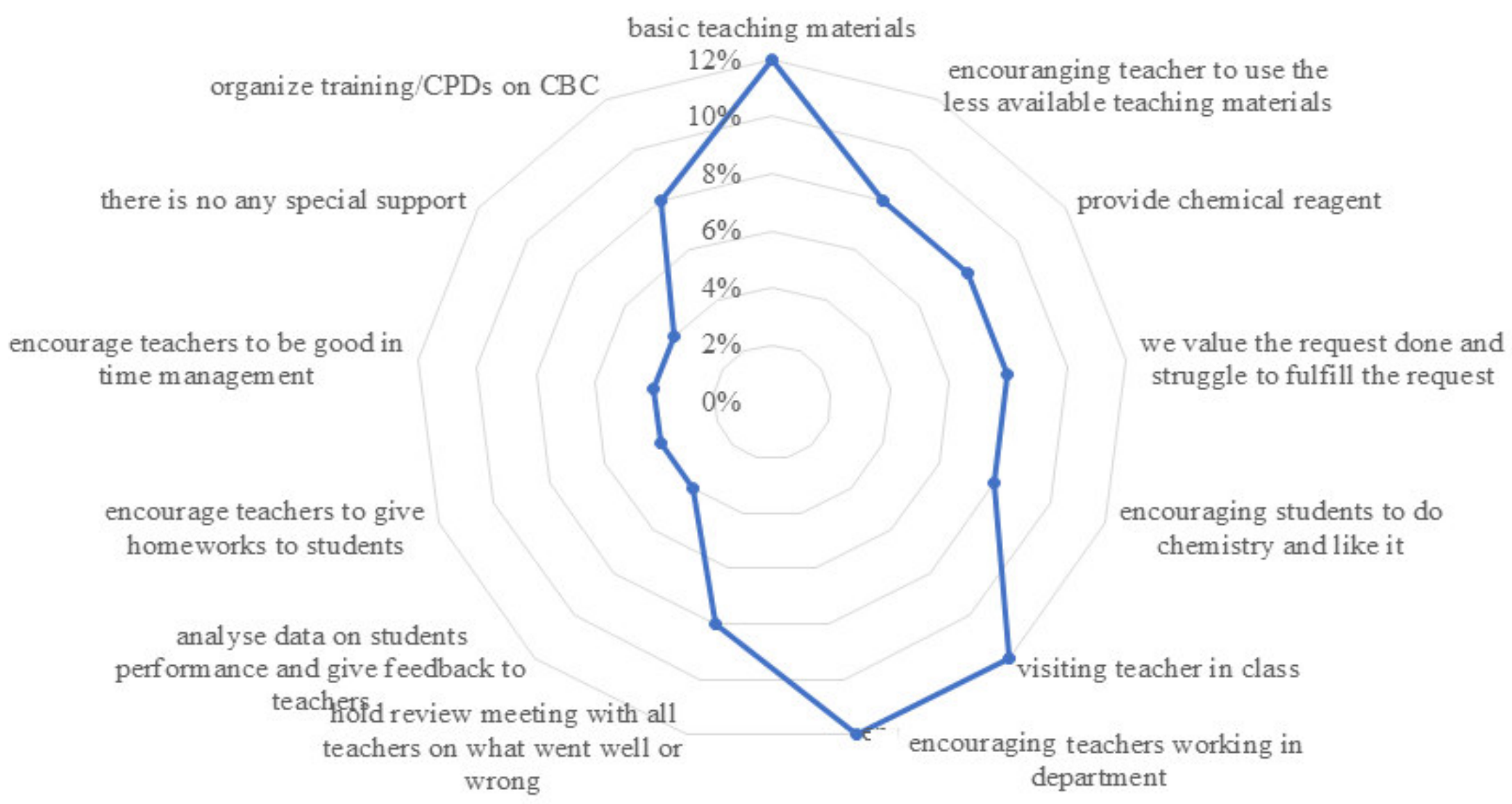

Figure 2 Areas for improvement in the support provided by headteachers 
The headteachers and deputy headteachers were very conscient that there are some areas which are critical that they have to work on; to reinforce their support as a school leader for the effective implementation of the CBC. They are aware of the gap in supporting chemistry teachers. Among many different areas that need much attention, only $30 \%$ of headteacher and deputy headteachers can manage to provide some basic teaching materials for smooth learning of chemistry subject; this was found to represent $12 \%$ of the support provided. The school leader should organise regular visits in the classroom to show his or her support to the teaching and learning process, and this is also done by only $30 \%$ of respondents; this was found to represent $12 \%$ of the support provided too. Another need highlighted, currently, only $30 \%$ of respondents do so too, this concerns the encouragement of teachers to work in chemistry departments for CPD to take place smoothly; again this was found to represent $12 \%$ of the support provided. Figure 3 below, presents the main challenges that interviewed school leaders encounter during their support to the implementation of the $\mathrm{CBC}$ in their schools.

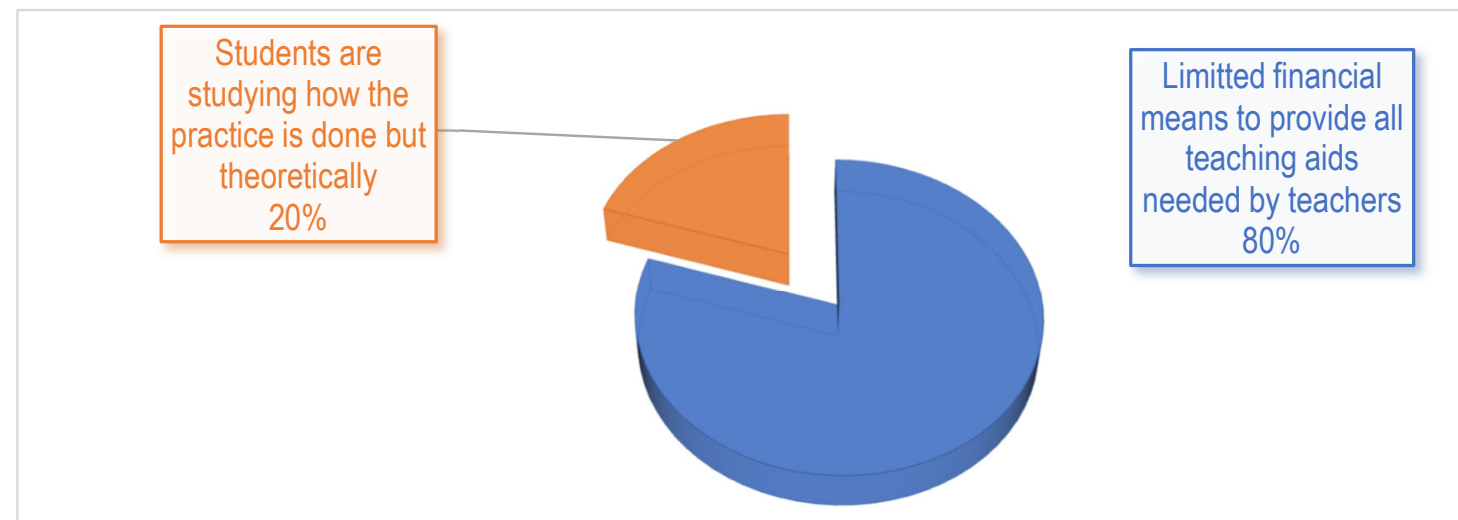

Figure 3 Main challenges faced by headteachers while supporting the implementation of CBC in their schools

The only $20 \%$ of respondents can manage to deal with the above gaps combined in their schools towards effective implementation of the $\mathrm{CBC}$ as the chemistry subject is concerned; this was found to represent $8 \%$ of the support provided. It is done by encouraging teacher to use the less available teaching materials. Provide chemical reagents for practice sessions and encouraging students to prefer chemistry and like it. Hold review meeting with all teachers on what went well or wrong and organising different CPDs on CBC. Whereas, only $10 \%$ of respondents can analyse the data on students performance and provide supportive or constructive feedback to teachers and inform decision-making practice; encouraging teachers to provide homework to students and encourage teachers to be good at time management during the teaching and learning process; all of them were found to represent $4 \%$ of the support individually. Across all schools visited, it was found that the support provided in teaching chemistry was dominated by $30 \%$ of respondents visiting teachers during the teaching and learning process. The other support by $30 \%$ too, is about encouraging teachers working in the department and provision of some basic teaching materials in chemistry classes by $30 \%$ of respondents.

The limited financial support to provide all teaching aids needed by teachers during the chemistry classes was highlighted as the main challenges that school leaders faced for their support to the $\mathrm{CBC}$ implementation, $80 \%$ of respondents claimed to have the budget challenge. The same, its implication of having students doing practical activities in chemistry classes in theory, was mentioned by $20 \%$ of respondents. This means that once the issue of teaching aids 
is solved; the capacity building for teachers to teach chemistry by incorporating the needed practical sessions will be required too.

\section{Discussion}

This part discusses the finding of the research. The headteacher is responsible for implementing the government policies that are relevant to the school level, including CBC implementation and the management of the teachers, including teachers' professional development. In Rwanda, headteachers, deputy headteachers and teachers are provided with the opportunities to follow CPD that supports to improve the quality of teaching and learning process (Ministry of Education, 2007). However, the result of headteachers and deputy headteachers' interviews reveals that CPDs for teachers are not prioritised in some schools, and this was found to hinder the effective implementation of CBC in different schools (Sahagun \& Matriano, 2019). The CPD is the right of the teacher and the right way to support the teacher in Rwanda (Republic of Rwanda, 2020).

The group work was found to be the most frequently used technique in teaching chemistry in schools. This is confirmed by $90 \%$ of respondents. It is the most preferred by $50 \%$ of the headteachers because of the large number of students in the class. Another reason given by the school leaders was the fact that the group related activities play a significant role in students' mutual support where leaners who are good at the subject support those that are still struggling in knowledge, skills, values and attitudes acquisitions. But the issue of those group work that teachers used are not yet fully engaging students in chemistry; teachers are still dominating the classroom activities rather than students do (Byusa et al., 2020).

Textbooks were observed to be used too, but surprisingly, none of the respondents has a preference in its use. Even though a book which is well organised contributes to the proper understanding of chemistry content in secondary school (Milanovic, Trivic, \& Tomasevic, 2015). However, for some chemistry content such as inorganic functions, books were found confusing to learners. For other content like polymer, books were not providing all that is needed to learn. So, teachers should use recently published paper than books (Quadros et al., 2011). Another example of the content whereby books are not appropriate is the use of different models for acids and bases. A critical review of the chemistry books to be used in chemistry classes is highly needed (Drechsler, 2007). Headteachers should support the S2 chemistry teachers to do the critical review of chemistry books to avoid confusions but to achieve the learning outcomes, as some of those content above are taught at the initial stage in S2.

It was also found that mentoring and coaching is needed to keep motivating both teachers and learners in science classes. Headteachers who are more proactive with the ability to motivate all school stakeholders, their schools were more likely to perform better than others (Singh \& Allison, 2016). It was found again that teachers who feel supported by the school leader, performed better because of the positive working environment (Schleicher, 2012).

The few available materials at school must be used too, in the proper way that supports the teaching and learning process. The close follow-up of the headteacher on the daily school life is key to success, including the academic performance in chemistry. For the effective implementation of the $\mathrm{CBC}$, the headteacher should lead the quality assurance evaluation of the school, promotes and leads the teacher's self-evaluation (Podgornik \& Vogrinc, 2017). The school leaders should keep reinforcing the collaboration of teachers by working in the chemistry department. Where there is no this practice of the collaboration through the chemistry department, schools should start it because it helps teachers to find out solutions together to the problem faced during teaching and learning of chemistry (Bantwini, 2019). 
For the effective teaching and learning of the chemistry, transformational leadership is required in the school. The school leaders to ensure that all school stakeholders, including students, teachers, support staff and parents, shared the same mission and vision of the school, is the pillar to the success of the school (Bantwini, 2019). The support of the school leaders should not be limited to the administrative matters only; the improved learning outcomes should be the target by all, meeting learning objectives and performance standards. The school leaders should be able to adjust the chemistry teaching to the local context, encourage professional teamwork, and engage in teachers and the teaching follow-up and CPDs. Again, school leaders need to be able to develop the school improvement plan; that shows strong alignment to the high-level decisions as well as locally expressed priorities, reflects inclusivity (gender, disability, environment and climate change mainstreaming considerations), implementable politically and technically, results-oriented, monitored and reviewed. They have to match the school needs and the hiring of the personnel (Schleicher, 2012) for effective implementation of the curriculum.

\section{Conclusion}

Headteachers play a significant role in the effective implementation of the CBC. They are responsible for all school matters, including teaching and learning, administration, and human resource management, including professional development opportunities. It was found that headteachers' involvement in what is needed to support the smooth running of the teaching and learning process varies in those ten selected schools.

With limited financial means, some schools are trying to support chemistry teaching with basic chemical reagent so that students can engage in practical sessions that have to be reinforced. The current school leaders' support is much dominated by soft support, such as encouraging teachers working in the department by $30 \%$ and visiting teachers during the teaching and learning process by $30 \%$ too. The provision of basic teaching materials in chemistry classes is done by $30 \%$ of respondents. There is a risk that teachers form groups as teaching technique of chemistry and then prioritise lecturing technique by hiding themselves in that formation of groups as applying active learning techniques. Teaching aids should be provided in chemistry classes to allow enough manipulation by students and CPDs for teachers to make classroom experience too attractive with better academic performance. This will contribute significantly to the effective implementation of $\mathrm{CBC}$. The promotion of positive learning environment has a significant positive impact on effective $\mathrm{CBC}$ implementation as the chemistry lesson is concerned.

Therefore, schools should be empowered enough to have teaching aids needed, and allocate enough time and opportunities to teachers' CPDs, encourage reflection meetings and learnings with headteachers. Collect, analyse classroom data for decision making that include school improvement planning, leading positive learning outcomes and a positive learning environment. Future studies may find out the reason why some schools do not prioritise the teachers' CPDs by according enough attention since it is the right of teachers.

Acknowledgements: This research was supported by the ACEITLMS. Thank you!

\section{References}

Bantwini, B. D. (2019). Developing a culture of collaboration and learning among natural science teachers as a continuous professional development approach in a province in 
African Journal of Educational Studies in Mathematics and Sciences Vol. 16, No. 1. 2020

South Africa. Teacher Development, 23(2), 213-232. https://doi.org/10.1080/13664530.2018.1533491

Byusa, E., Kampire, E., \& Mwesigye, A. R. (2020). Analysis of Teaching Techniques and Scheme of Work in Teaching Chemistry in Rwandan Secondary Schools. EURASIA Journal of Mathematics, Science and Technology Education, 2020, 16(6), Em1848, 16(6). https://doi.org/doi.org/10.29333/ejmste/7833

Creswell, J. W., \& Garrett, A. L. (2008). The "movement" of mixed methods research and the role of educators. South African Journal of Education, 28(3), 321-333. https://doi.org/10.4314/saje.v28i3.25155

Drechsler, M. (2007). Models in chemistry education - A study of teaching and learning acids and bases in Swedish upper secondary schools (Doctorate Dissertation). Karlstad University.

Michael, J. (2006). Where's the evidence that active learning works? Advances in Physiology Education, 30(4), 159-167. https://doi.org/10.1152/advan.00053.2006

Milanovic, V. D., Trivic, D. D., \& Tomasevic, B. I. (2015). Secondary-school chemistry textbooks in the 19th century. Journal of the Serbian Chemical Society, 80(10), 13211338. https://doi.org/10.2298/JSC140926052M

Ministry of Education. (2007). Teacher Development and Management Policy in Rwanda (2007th ed.). Kigali- Rwanda, Rwanda: Ministry of Education.

Ministry of Education. (2015). Competence-Based Curriculum Curriculum Framework: PrePrimary To Upper Secondary 2015. Kigali- Rwanda: WordCore Communications Limited.

Naz, F., \& Tatlah, P. I. A. (2011). The implementation of curricula at secondary level: Role of head teacher. International Journal of Learning, 17(12), 81-88. https://doi.org/10.18848/1447-9494/cgp/v17i12/47394

Ndihokubwayo, K., Mugabo, R. L., Byusa, E., \& Habiyaremye, H. T. (2019). Training Strategies Used in Straightening Competence-Based Curriculum in Rwanda. Švietimas: Politika, Vadyba, Kokybe / Education Policy, Management and Quality, 11(2), 77-87.

Ndihokubwayo, K., \& Murasira, G. (2019). Teachers' training college learners' expectations for their future teaching career. LWATI: A Journal of Contemporary Research, 16(2), $1-19$.

Podgornik, V., \& Vogrinc, J. (2017). The Role of Headteachers , Teachers , and School Counselors in the System of Quality Assessment and Assurance of School Work. SAGE Open, (April-June 2017), 1-13. https://doi.org/10.1177/2158244017713239

Quadros, A. L. de, CarvalhoDa-Silva, D., Silva, F. C., Andrade, F. P. de, Aleme, H. G., Tristão, J. C., ... DeFreitas-Silva, G. (2011). The knowledge of chemistry in secondary education: difficulties from the teachers' viewpoint. Educacion Quimica, 22(3), 232239.

Republic of Rwanda. Ministerial Order $\mathrm{N}^{\circ} 002 / 2016$ of 08/01/2016 determining the responsibilities of school management board members, Pub. L. No. Official Gazette $n^{o}$ 03 of 18/01/2016, 16 (2016). Rwanda.

Republic of Rwanda. Presidential Order No 064/01 of 16/03/2020 establishing special statutes governing teachers in nursery, primary, secondary and technical and vocational schools, Pub. L. No. Official Gazette n 10 of 16/03/2020, 3 (2020). Rwanda. 
Ways School Leaders Support the Teaching of Chemistry

Edwin Byusa, Edwige Kampire \& Adrian Rwekaza Mwesigye

Sahagun, J. A. P., \& Matriano, E. A. (2019). Impacts of Continuing Professional Development (CPD) Activities among Elementary School Teachers. IMRaD Journal, a PeerReviewed and Refereed Institutional Multidisciplinary Research and Development Journal, 2(July). https://doi.org/10.13140/RG.2.2.13185.20321

Schleicher, A. (2012). Preparing Teachers and Developing School Leaders for the 21st Century: Lessons from around the World. OECD Publishing. https://doi.org/10.1787/9789264174559-en

Singh, S. B., \& Allison, D. J. (2016). School Leadership Practices of Headteachers in Kathmandu. International Studies in Educational Administration, 44(Number 3, 2016), 75-91.

Tenaw, Y. A. (2015). Effective strategies for teaching chemistry. International Journal of Education Research and Reviews, 3(3), 78-84.

TheNewTimes. (2017). Sciences: Why lack of labs remains a stumbling block. Retrieved from https://www.newtimes.co.rw/section/read/208236

World Bank. (2003). Education in Rwanda: Rebalancing Resources to Accelerate PostConflict Development and Poverty Reduction (A World Bank country study). Washington, D.C: THE WORLD BANK. Retrieved from http://siteresources.worldbank.org/INTAFRICA/Resources/Rwanda_ED_CSR.pdf 